\title{
Quality inspection of a 2.85 MW PV power plant under mismatch loss due to different classes of PV module installed
}

\author{
J.A.Clavijo-Blanco ${ }^{1}$, G. Álvarez-Tey ${ }^{1}$, N. Saborido-Barba ${ }^{1}$, J.L. Barberá-González ${ }^{1}$, C. García- \\ López $^{1}$ and R. Jimenez-Castañeda ${ }^{1}$ \\ ${ }^{1}$ Department of Electrical Engineering \\ School of Engineering, University of Cádiz \\ Avenida Universidad de Cádiz, 10. Puerto Real-Cádiz (Spain) \\ Phone:+0034 956 483200, e-mail: joseantonio.clavijo@uca.es, german.alvarez@uca.es, nieves.saborido@uca.es, \\ joseluis.barberagonzalez@alum.uca.es, carmen.garcia@uca.es, rafael.castaneda@uca.es
}

\begin{abstract}
.
In this paper, the quality inspection of a Photovoltaic (PV) power plant under a mismatch effect due to the use of 18 different classes of PV modules from 5 different manufacturers is presented. The quality inspection has been carried out by three different tests; a visual inspection, an infrared (IR) thermography inspection and electrical monitoring. More than 800 IR thermography images have been analyzed to cover all PV modules installed. Some inverters have been electrically monitored to measure electrical parameters, being the focus of this paper the output energy. A PV plant database has been studied to calculate a mismatch power factor of the PV arrays connected in the measured inverters. Mismatch power factor, hot spots and the output energy of the measured inverters have been compared. Results showed that output energy is influenced by the existence of mismatching. In some cases, compared inverters showed a power loss of up to $10 \%$.
\end{abstract}

Keywords. Mismatch loss, IR thermography, quality inspection, maintenance, performance.

\section{Introduction}

PV solar energy installed capacity in Spain had been growing exponentially up to the year 2008 according to the European Photovoltaic Industry Association (EPIA) [1]. In 2007 the power PV capacity was 560 MW while in 2008 it was increased up to 2,511 MW. It supposed an increase of 448\% which ranked Spain as the first PV world installed cumulative capacity. The recorded exponential growth was mainly caused by the premiums provided by the Spanish government to the exploitation of PV plants, which stopped in 2008. From 2008 up to date there has been a soft growth of the installed capacity, [2], due to the lack of investor and subsidies. Such increase in 2008 was a disadvantage to the manufactures since the demand for PV modules was difficult to supply. To meet the demand, some PV plants had to be supplied by different classes of PV modules. So, despite the effort of electrical installation companies, notable difficulties were found to cluster different PV modules classes to connect a PV array. The connection of such variability of $\mathrm{PV}$ modules produces electrical mismatches and the consequent loss of power in the PV power plant [3]. The PV plant under inspection has a nominal power of $2.85 \mathrm{MW}$ and was commissioned in 2008.

As it is broadly known in PV parks, PV modules are electrically connected in series and parallel circuits. When PV modules connected have different electrical properties, mismatch losses occur. There are different circumstances in a PV park which can produce mismatch effects. The first circumstance could be given when the irradiance reached in a PV array is non-uniform, which can be produced by partial shading or soiling. Partial shading caused by clouds, nearby objects or even the partial soiling caused by the lack of cleaning in PV arrays produces electrical mismatch which affects the performance of photovoltaics installation [4][5]. A second circumstance is given by the fact that two identical PV modules built by the same manufacturer have notable differences between their electrical parameters due to fabrication spread[3]. For this reason, apart from the datasheet, where an uncertainty associated with the nominal power output is shown, some manufacturers provide a flash report (FR). FR allows knowing exactly the electrical parameters of each PV module. A third finally circumstance could be given by the connection of different classes of PV modules in the same PV array, which increases the losses produced by the fact exposed in the second reason, which is the case studied in the present paper. However, under operation condition, a different scenario could take place when a faulty PV module is replaced by a new one. When a first-installed PV module brand is out of the market, it is common to replace it by one as similar as possible, producing electrical mismatches in the PV generator. In this case, the replacement has to be done having into account the degradation of the PV array where the new one is going to be placed [3].

It is worth noticing that the produced energy along the lifetime of a PV plant plays an important role since incomes depend strongly on it. So, the evaluation of the quality, reliability and electrical performance of a PV plant is important to test and analyze its correct behavior.

Visual inspection is a well-known method used to detect faults by visual analysis of a PV array. This method allows 
observing PV cell surface color changes and visible defects of PV modules [6]. This is the simplest and fastest method to detect defects and visible faults such as delamination, discoloration, yellowing, browning, bending, burn marks, glass breakage and broken and cracked cells, [7], [8], [9]. Visual inspection is also used to identify temporary failures which can be solved by suitable maintenance, such as, dust, dirt, bird droppings and shadow [10].

However, there are many other causes that can reduce the performance of a PV array. One of the most studied causes is hot-spots. Not all hot spots are detected through visual inspection. For this reason, it is necessary to apply other methods for their detection. The hot-spot causes serious problem shorting the lifetime and decreasing the efficiency of a PV module [11]. Considering the published bibliographic review, recent advances, ongoing research and future perspectives on the characteristics and classification of common faults in PV modules, advanced diagnosis has been used using infrared thermal imaging, [8], [12] [13], [14]. The importance of a photovoltaic cell/module operating temperature for its electrical performance is well known, as well as the necessity for in situ fast and reliable monitoring techniques for PV installations efficiency [15].

The infrared (IR) thermography is a non-destructive technique (NDT) which is used to carry out maintenance quickly and easily in photovoltaic (PV) systems [16]. IR thermography is a suitable tool to detect and locate nohealthy PV modules by their temperature profile under real operating conditions. The performance of defective modules is determined significantly by the operating conditions such as solar irradiation, working temperature, string configuration determining the working point, etc. [17].

Terrestrial IR thermography is a traditional method used for the inspection of both small PV installations and industrial PV plants. On the other hand, Unmanned Aerial Vehicle (UAV)-based aerial thermography has become a convenient quality assessment tool for photovoltaic power plants [18]. For the proper IR inspection which determines the importance of the detected anomalies, it is necessary to consider different aspects of the configuration and the location of the thermographic equipment which allow reducing measuring errors [16].

Energy output or some other electrical parameters could be measured by the connection of electric power analyzers. An example is shown in [8] or [19], where some authors have measured the output power of a PV plant to study the presence of pollution and dust on the panel surface.

The main objective of this paper is to present a quality inspection methodology and quantitative research of a PV plant operating with up to 18 different classes of PV modules. It is organized as follows: in the next section, as the features of the PV plant as the methodology stablished to make the quality inspection is described. Results obtained are discussed in Section 3. Finally, the conclusions are given in Section 4.

\section{Methodology}

The PV plant under inspections is located in the south of Spain and it was commissioned in 2008. The PV plant is formed by 13485 polycrystalline PV modules connected through 29 inverters to reach a nominal power of $2.85 \mathrm{MW}$. The quality inspection has been performed in May 2019 and a total of 18 classes of different PV modules of 5 different manufacturers have been found. Features of each PV module class are shown in table 1.

Table 1. Features of PV modules installed

\begin{tabular}{|c|c|c|c|c|c|c|c|}
\hline $\begin{array}{c}\text { PV } \\
\text { module } \\
\text { Brand }\end{array}$ & $\begin{array}{c}\text { PV } \\
\text { module } \\
\text { class } \\
(\mathbf{W p})\end{array}$ & $\begin{array}{c}\text { Vmp } \\
(\mathbf{V})\end{array}$ & $\begin{array}{c}\text { Imp } \\
(\mathbf{A})\end{array}$ & $\begin{array}{c}\text { Voc } \\
(\mathbf{V})\end{array}$ & $\begin{array}{c}\text { Isc } \\
(\mathbf{A})\end{array}$ & $\begin{array}{c}\text { Maximum } \\
\text { Power } \\
(\mathbf{M P})(\mathbf{W})\end{array}$ & $\begin{array}{c}\text { Tolerance } \\
\text { of max. } \\
\text { power } \\
\text { rating (\%) }\end{array}$ \\
\hline Brand 1 & 270 & 36.40 & 7.42 & 43.63 & 8.10 & 270.00 & \pm 3 \\
\hline & 195 & 24.53 & 7.96 & 29.52 & 8.46 & 195.00 & \pm 5 \\
\cline { 2 - 8 } & 200 & 24.96 & 8.03 & 29.76 & 8.52 & 200.00 & \pm 5 \\
\cline { 2 - 8 } & 205 & 29.58 & 6.93 & 35.94 & 7.47 & 209.90 & \pm 5 \\
\cline { 2 - 8 } Brand 2 & 210 & 29.64 & 7.09 & 35.94 & 7.60 & 214.90 & \pm 5 \\
\cline { 2 - 8 } & 215 & 29.94 & 7.18 & 36.00 & 7.83 & 219.90 & \pm 5 \\
\cline { 2 - 8 } & 220 & 30.12 & 7.30 & 36.06 & 7.95 & 224.90 & \pm 5 \\
\cline { 2 - 8 } & 225 & 30.36 & 7.41 & 36.42 & 8.10 & 229.90 & \pm 5 \\
\cline { 2 - 8 } & 230 & 30.48 & 7.55 & 36.60 & 8.17 & 234.90 & \pm 5 \\
\hline \multirow{5}{*}{ Brand 3 } & 210 & 46.60 & 4.51 & 57.90 & 4.94 & 210.00 & \pm 5 \\
\cline { 2 - 8 } & 220 & 46.90 & 4.69 & 58.40 & 5.10 & 220.00 & \pm 5 \\
\cline { 2 - 8 } & 230 & 47.50 & 4.84 & 58.80 & 5.25 & 230.00 & \pm 5 \\
\cline { 2 - 8 } & 235 & 29.80 & 7.90 & 36.90 & 8.46 & 235.00 & \pm 5 \\
\hline \multirow{3}{*}{ Brand 4 } & 240 & 48.10 & 4.99 & 59.30 & 5.40 & 240.00 & \pm 5 \\
\cline { 2 - 8 } & 210 & 28.99 & 7.38 & 36.02 & 8.03 & 210.00 & \pm 5 \\
\cline { 2 - 7 } & 220 & - & - & - & - & - & \pm 5 \\
\hline Brand 5 & 260 & 34.10 & 7.59 & 36.14 & 8.38 & 220.00 & \pm 5 \\
\hline
\end{tabular}

A database provided by the PV plant operation company has been studied in this paper. According to database, PV modules brand $1(27.12 \%), 2(64.50 \%)$ and $3(6.67 \%)$ were originally installed in the PV plant, while PV module brand $4(1.42 \%)$ and $5(0.28 \%)$ has been used to replace nohealthy PV modules brand 2 and 1 respectively. The database contained flash report data of PV modules brand 1 and 2, about $90 \%$ of the power plant, while the flash report of PV modules brand 3, brand 4 and 5 were not available.

To the quality inspection of the PV plant, a procedure focused to study the mismatch loss has been carried out. The quality inspection has been performed through the study of three different tests: visual inspection, IR thermography and electrical monitoring. Tests have been based on the proceeding published by the International Electrotechnical Commission (IEC) in [20], [21], [22] and [23].

PV modules were addressed in the PV plant through an electrical codification which was difficult to take in practice. So, a new codification focused on the physical location of a PV module has been established. This codification has allowed to write down those PV modules with defects and be easily found after finishing the inspection. The physical codification established has been:

F00-AF00-NA00-“00”

Where;

- F; PV tables row 
- AF; physical aggrupation of PV modules, usually known as "PV module tables". From the back-side view of PV tables, the first one is located on the right.

- NA; height level where a PV module is located in a PV module table.

- "00"; Number of the PV module. From the back-side view of PV modules, the first one is located on the right.

Figure 1 shows an example of the localization of the PV module F02-AF02-NA2-5. Physically, The PV module F02-AF02-NA2-5 is located in row number 2, PV module table 2, height level 2, PV module number 5.
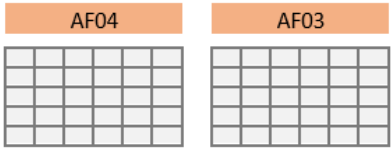

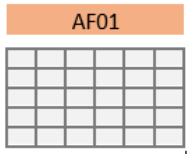

F02. Back-side view
Fig. 1. PV module location. Physical codification example.

IR imaging with thermographic cameras in steady-state conditions is a common method for quality control of photovoltaic modules and plants in operation. Initially, an air-drone IR thermography inspection was proposed. However, it was cancelled due to a nearby location of an airport. So, the temperature has been measured at the rear side of PV modules by terrestrial IR thermography. FLIR Systems, model ThermaCAM S60 has been the IR thermography used. According to [24] and [25], images resolution obtained in a terrestrial thermographic inspection were better than those obtained in aerial thermographic, which has allowed obtaining better results.

IR thermographic must be properly applied to obtain precise temperature values. So, to reduced measurement errors, the IR camera configuration to carry out the inspection has been established according to [16], where the following aspects must be taken into account:

1.- The importance of the apparent reflected temperature in outdoor inspections measured by an infrared reflector.

2.- To consider the emissivity of the PV modules, according to the inspection place.

As a result, the whole PV plant has been thermally inspected, and more than 800 IR thermography images have been studied by the software ThermaCAM Researcher Pro 2.7.

The PV plant under inspection had a nominal power of 2.85 MW. It was formed by 29 inverters, of which 28 had a nominal power of $100 \mathrm{~kW}$ and 1 had a nominal power of $50 \mathrm{~kW}$. Due to the available time, which was established in 3 days, to perform the electrical monitoring inspection, not all inverter could be measured. So, a total of 8 inverters has been measured and analyzed during the inspection time. Inverters have been chosen according to the number of different PV modules classes connected. So, to study the influence of mismatching effect in each inverter in steadystate condition, two Fluke 435-II Power Quality and Energy Analyzers have been simultaneously connected in two different inverters to compare measurement. So, four pairs of measures were taken in a total of 8 inverters:

- First comparison: inverters N20 and N28.

Measure time: from 17:20h to 9:35h

- Second comparison: inverters N18 and N27.

Measure time: from 10:58h to 16:09

- Third comparison: inverters N1 and N6.

Measure time: from 17:01h to 8:35h

- Forth comparison: inverters N8 and N10.

Measure time: from 09:00 h to $11: 42 \mathrm{~h}$

Table 2 shows the different classes of PV modules connected in each inverter, the numbers of PV modules of different classes ( $\mathrm{N}^{\circ}$ of PV $\mathrm{M}$ ) and the peak power of each PV array (PV A PP) connected to each inverter, where letters $\mathrm{N}, \mathrm{B}$ and $\mathrm{C}$ mean inverter, brand and class respectively. Five inverters were composed by different classes of PV modules while the other tree inverters were formed only by one class of PV module. PV arrays of N20, $\mathrm{N} 1$ and N8 shared the same class of PV modules while PV arrays of N28, N27, N18, N6 and N10 shared up to 4 different classes of PV modules.

Table 2. Classes of PV modules connected in each inverter

\begin{tabular}{|c|c|c|c|c|}
\hline $\mathrm{N}$ & $\mathrm{B}$ & $\mathrm{C}$ & $\mathrm{N}^{\circ}$ of PV M & PV A PP \\
\hline $\mathrm{N} 20$ & Brand 2 & $225 \mathrm{Wp}$ & 494 & $111.15 \mathrm{kWp}$ \\
\hline \multirow{3}{*}{$\mathrm{N} 28$} & \multirow{3}{*}{ Brand 2 } & $200 \mathrm{Wp}$ & & \\
\cline { 3 - 3 } & & $205 \mathrm{Wp}$ & \multirow{2}{*}{540} & $112.10 \mathrm{kWp}$ \\
\cline { 3 - 3 } & & $210 \mathrm{Wp}$ & & \\
\cline { 3 - 3 } & & & \\
\hline
\end{tabular}

\begin{tabular}{|c|c|c|c|c|}
\hline \multirow{2}{*}{ N27 } & \multirow{2}{*}{ Brand 2 } & $215 \mathrm{Wp}$ & \multirow{2}{*}{520} & \multirow{2}{*}{$109.30 \mathrm{kWp}$} \\
\cline { 3 - 3 } & & $220 \mathrm{Wp}$ & & \\
\cline { 3 - 3 } N18 & \multirow{2}{*}{ Brand 3 } & $210 \mathrm{Wp}$ & \multirow{2}{*}{446} & $102.00 \mathrm{kWp}$ \\
\cline { 3 - 3 } & $230 \mathrm{Wp}$ & & \\
\hline
\end{tabular}

\begin{tabular}{|c|c|c|c|c|}
\hline N1 & Brand 1 & $270 \mathrm{Wp}$ & 408 & $110.16 \mathrm{kWp}$ \\
\hline \multirow{2}{*}{ N6 } & \multirow{3}{*}{ Brand 2 } & $205 \mathrm{Wp}$ & & \\
& & $210 \mathrm{Wp}$ & \multirow{2}{*}{540} & $112.50 \mathrm{kWp}$ \\
& & $215 \mathrm{Wp}$ & & \\
\hline
\end{tabular}

\begin{tabular}{|c|c|c|c|c|}
\hline \multirow{2}{*}{ N10 } & \multirow{2}{*}{ Brand 2 } & $215 \mathrm{Wp}$ & \multirow{2}{*}{500} & $109.90 \mathrm{kWp}$ \\
\cline { 3 - 3 } & & $220 \mathrm{Wp}$ & & \\
\hline N8 & Brand 2 & $210 \mathrm{Wp}$ & 520 & $109.20 \mathrm{kWp}$ \\
\hline
\end{tabular}

To establish a level of mismatch in each PV array, the flash report of each PV array connected in the measured inverters have been studied. Table 3 shows the lower (LVMP), average (AVMP) and higher (HVMP) value of PV modules maximum power point (MPP) connected in each inverter. A mismatch power factor (MPF) has been calculated and included in table 3. MPF measures the power difference between the PV module with the higher and the lower maximum power point in the same inverter.

In fig. 2, it has been represented PV modules MPP of inverters N20 and N28 according to flash report database. PV modules installed in N20 had higher MPP values than in N28. However, in N28 there were more PV modules connected. In N28 can be observed the variability of the dates due to the use of different PV modules classes, so mismatch power rate was higher in N28 than in N20. 
Table 3. Mismatching values

\begin{tabular}{|c|c|c|c|c|c|c|}
\hline N & B & C & LVMP & AVMP & HVMP & MPF (W) \\
\hline N20 & Brand 2 & $225 \mathrm{Wp}$ & 215.14 & 224.47 & 231.34 & 16.20 \\
\hline \multirow{3}{*}{ N28 } & \multirow{3}{*}{ Brand 2 } & $200 \mathrm{Wp}$ & & & & \\
& & $205 \mathrm{Wp}$ & \multirow{2}{*}{200.01} & 207.27 & 226.54 & 26.53 \\
& & & & & \\
& & $215 \mathrm{Wp}$ & & & & \\
\hline
\end{tabular}

\begin{tabular}{|c|c|c|c|c|c|c|}
\hline \multirow{3}{*}{ N27 } & \multirow{3}{*}{ Brand 2} & $215 \mathrm{Wp}$ & \multirow{3}{*}{200.88} & \multirow{3}{*}{219.45} & \multirow{3}{*}{232.49} & \multirow{3}{*}{31.61} \\
\hline & & $220 \mathrm{Wp}$ & & & & \\
\hline & & $225 \mathrm{Wp}$ & & & & \\
\hline \multirow{2}{*}{ N18 } & \multirow{2}{*}{ Brand 3} & $210 \mathrm{Wp}$ & \multirow{2}{*}{$\begin{array}{c}\text { NO } \\
\text { DATA }\end{array}$} & \multirow{2}{*}{$\begin{array}{c}\text { NO } \\
\text { DATA }\end{array}$} & \multirow{2}{*}{$\begin{array}{c}\text { NO } \\
\text { DATA }\end{array}$} & \multirow{2}{*}{37.40} \\
\hline & & $230 \mathrm{Wp}$ & & & & \\
\hline
\end{tabular}

\begin{tabular}{|c|c|c|c|c|c|c|}
\hline N1 & Brand 1 & $270 \mathrm{Wp}$ & 261.94 & 270.57 & 283.14 & 21.21 \\
\hline \multirow{2}{*}{ N6 } & \multirow{2}{*}{ Brand 2 } & $205 \mathrm{Wp}$ & \multirow{2}{*}{200.06} & \multirow{2}{*}{207.04} & 225.52 & \multirow{2}{*}{25.46} \\
\cline { 3 - 3 } & & $210 \mathrm{Wp}$ & & & \\
\cline { 3 - 3 } & & & & & & \\
\hline
\end{tabular}

\begin{tabular}{|c|c|c|c|c|c|c|}
\hline \multirow{2}{*}{ N10 } & \multirow{2}{*}{ Brand 2 } & $215 \mathrm{Wp}$ & \multirow{2}{*}{205.45} & 219.89 & 231.98 & 26.53 \\
\cline { 3 - 5 } & & $220 \mathrm{Wp}$ & & 210.27 & 219.89 & 16.82 \\
\hline N8 & Brand 2 & $210 \mathrm{Wp}$ & 203.07 & 210 \\
\hline
\end{tabular}

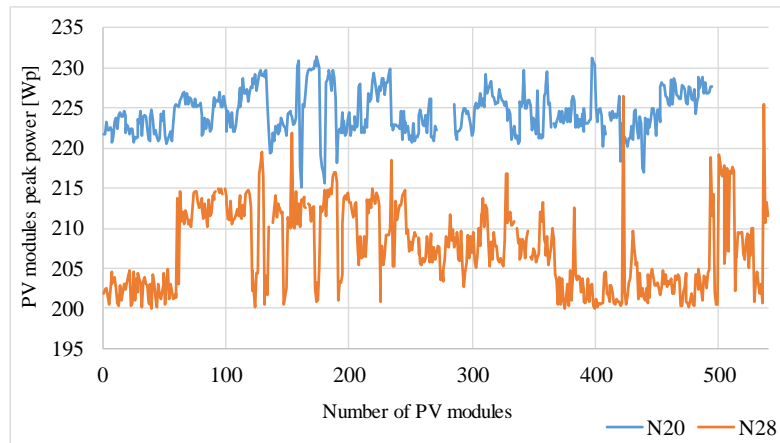

Fig. 2. Comparison of data on mismatching in N20 and N28

As there was no flash report data for the PV array connected in N18, the LVMP and HVMP values have been calculated theoretically through the tolerance of maximum power rating according to PV module datasheet. So, the lower, and higher value of each PV module has been obtained as equations 1 and 2 show:

$L V M P=P_{M P P \min i}=P_{M P P}-\left(P_{M P P} \cdot\right.$ Tolerance $)$

$H V M P=P_{M P P \max i}=P_{M P P}+\left(P_{M P P} \cdot\right.$ Tolerance $)$

Where;

$P_{M P P \min i} ;$ minimum MPP possible for a PV module brand $\mathrm{i}$ $P_{M P P \max i}$; maximum MPP possible for a PV module brand $\mathrm{i}$ $P_{M P P}$; MPP of a PV module (Power Class)

As N18 shared two different classes of PV modules, $230 \mathrm{Wp}$ and $210 \mathrm{Wp}$, the MPF has been determined as equation 3 shows:

$$
M P F=H V M P(230 W p)-L V M P(210 W p)
$$

So, in Fig 3, HVMP and LVMP of PV modules in N18 has been compared with PV modules MPP of inverters N27 according to the flash report database. In N27 there were more PV modules connected than in N18. As both inverters had the same number of different classes of PV modules connected, the variability of dates in N27 and N18 were similar. However, the MPF is higher in N18 than in N20.

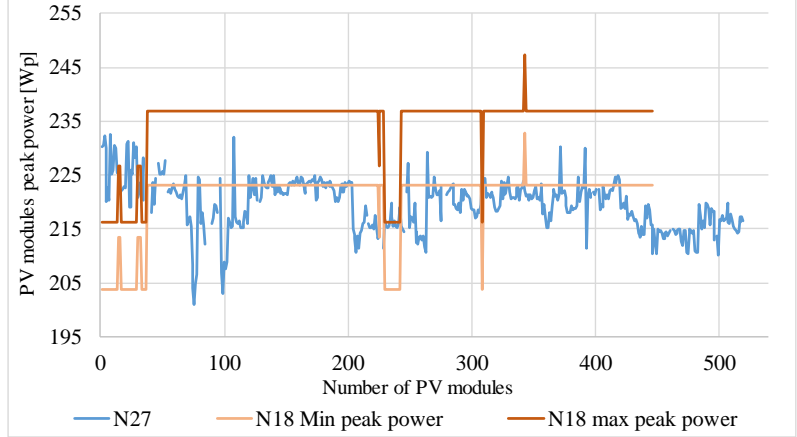

Fig. 3. Comparison of data on mismatching in N27 and N18

In fig. 4, it has been represented PV modules MPP of inverters N1 and N6 according to the flash report database. PV modules installed in N1 had higher MPP values than in N6. However, in N6 there were more PV modules connected. In N6 can be observed the variability of the dates due to the use of different PV modules classes, so MPF was higher in N6 than in N1.

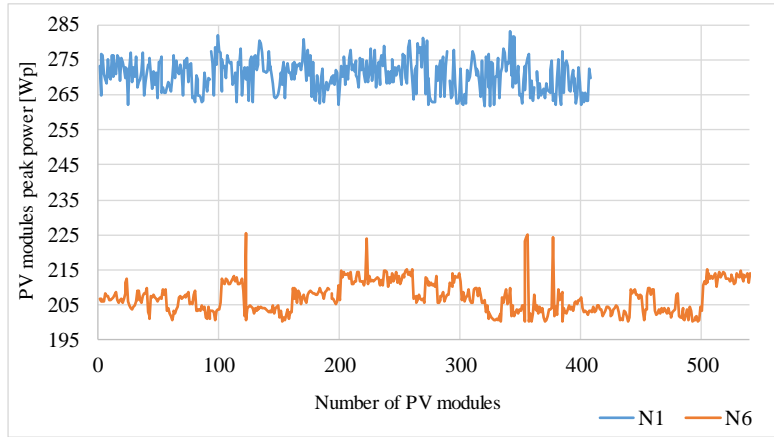

Fig. 4. Comparison of data on mismatching in N1 and N6

In fig. 5, it has been represented PV modules MPP of inverters N10 and N8 according to the flash report database. PV modules installed in N10 had higher MPP values than in N8. However, in N8 there were more PV modules connected. In N10 can be observed the variability of the dates due to the use of different PV modules classes, so mismatch MPF was higher in N10 than in N8.

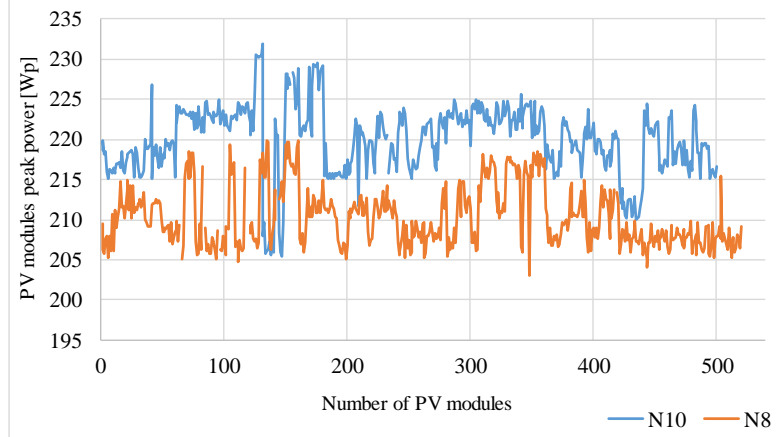

Fig. 5. Comparison of data on mismatching in N10 and N8

\section{Results}

Once the visual inspection of the PV plant has been carried out, several defects have been found. Defects found in the PV plant has been: anti-reflective layer discoloration, browning, yellowing, burned PV cells, snail tracks, milky front-glass, broken front-glass, and the connection of different PV modules classes coming from several 
manufacturers in the same string. Figure 6 shows some defects found. It is worth to highlight the lack of cleaning under the evidence of soiling and bird dropping.

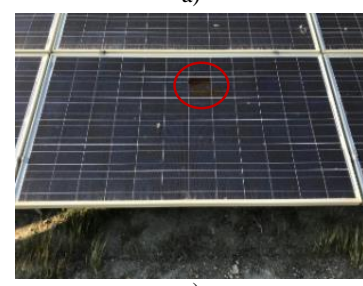

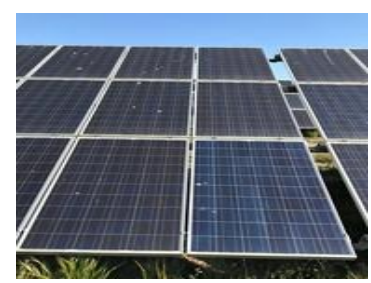
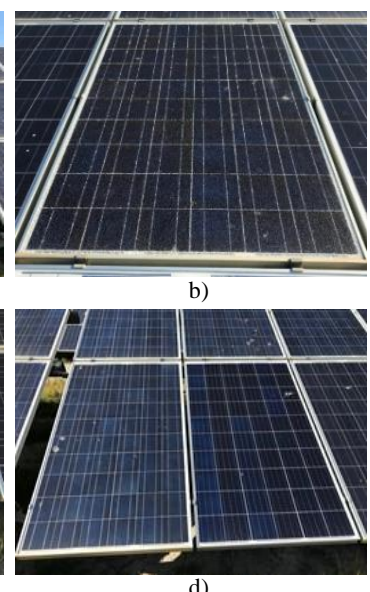

Fig. 6. Some defects found in the visual inspection. a) discoloration, b) broken front-glass, c) burned PV cell, d) connection of different PV modules

More than 800 IR images have been analyzed and a total of 117 IR images shown thermal anomalies in PV modules. Fig.7 shows different thermal anomalies found through the 117 images. 103 IR images, $88 \%$ of the total, have been caused by hot spots, which mean less than $1 \%(0.76 \%)$ of the whole PV power plant. Some PV modules defects found in the IR thermography inspections have been also found in the visual inspection. Fig. 8 shows a PV module with 2 burned PV cells with its thermal response detected at the rear of the PV module in the IR thermographic inspection. The temperature reached in the hot spot was $91.6{ }^{\circ} \mathrm{C}$.

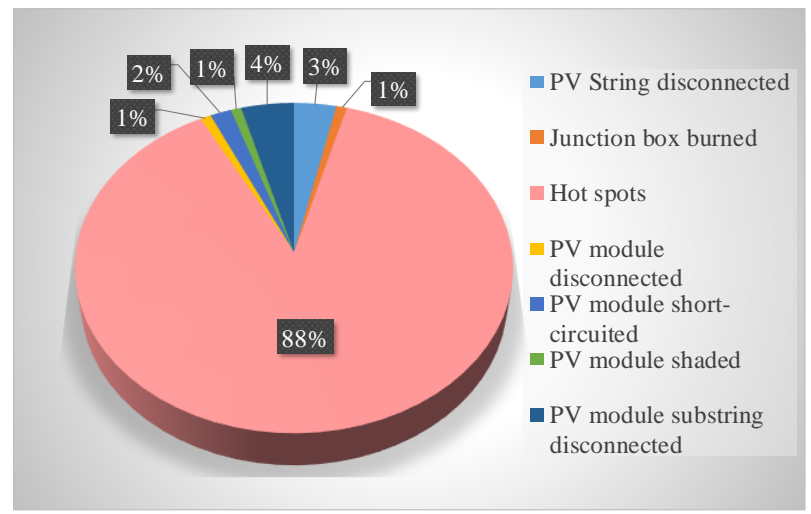

Fig. 7. Defects found in the IR thermal inspection

In some cases, unlike it is shown in Fig. 8, the IR thermal inspection detected hot spots that were not detectable in the visual inspection. A considerable problem is caused by the fact that PV modules affected by hot spots not only have a reduction of its own efficiency but also it could cause a reduction of the generation capacity of the whole string where it is connected [5].

PV modules affected by hot spots have been classified depending on their brand, where the $35 \%$ and $58 \%$ were caused in PV modules brand 1 and 2 respectively. This result did not mean that these two PV modules brand had less quality than other brands since it depends on the numbers of each PV module brand installed in the plant. To be able to compare each PV module brand, a hot spot rate $(\lambda)$ has been calculated as equation 4 shows:

$$
\lambda_{i}=\frac{\text { number of } P V \text { modules brand } i \text { affected by hot spot }}{\text { total of } P V \text { modules brand } i}
$$
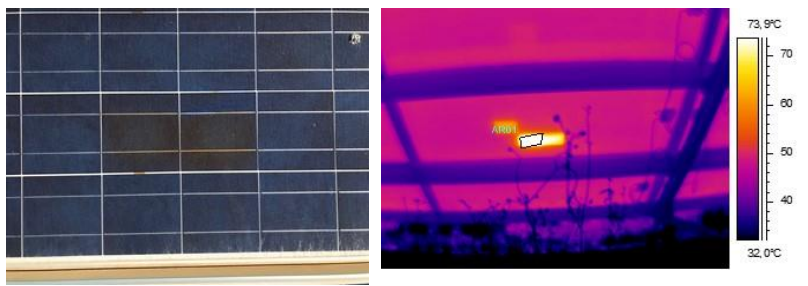

Fig 8. PV module with burned PV cell.

Table 4 shows $\lambda$ of each PV module brand obtained, where the highest value has been given by PV module brand 1 , which matched with the PV module class with the highest MPP. The hot spot rate in PV module brand 2 and 3 have been similar while PV module brand 4 has been the lowest value.

Table 4 . Hot spot rate $(\lambda)$ by PV module brand

\begin{tabular}{cc} 
PV module brand & $\lambda$ \\
\hline Brand 1 & $0.984 \%$ \\
Brand 2 & $0.690 \%$ \\
Brand 3 & $0.667 \%$ \\
Brand 4 & $0.521 \%$
\end{tabular}

The relationship between the MPF, hot spots, PV array peak power and the output energy measured in the compared inverters is shown in Fig.9.

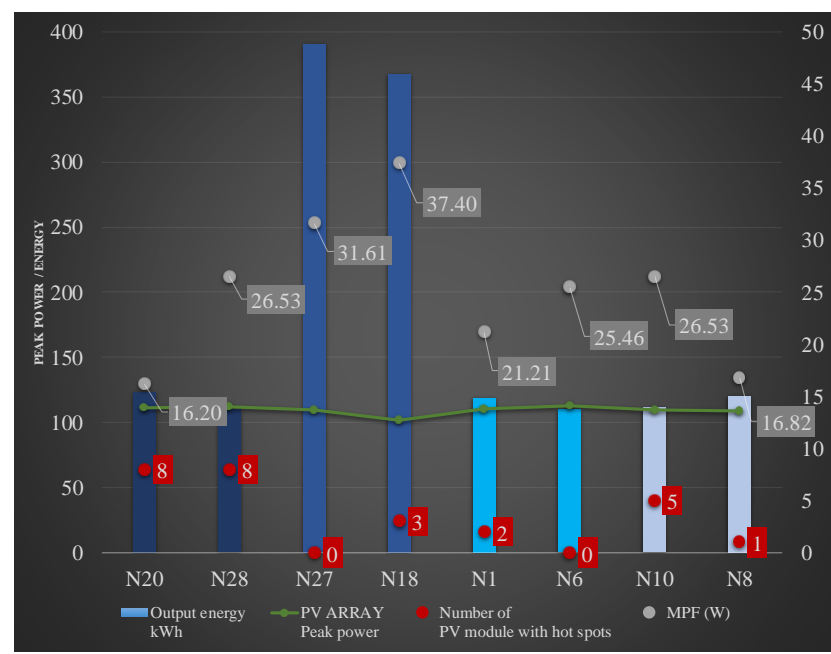

Fig. 9. Peak power, mismatch, hot spot and energy relationship in the compared inverters.

Compared inverters N20-N28, N27-N18, N1-N6 and N10N8 have almost produced the same energy, which indicates its homogeneous operation. However, there were some differences in output energy. Inverters with higher values of mismatching rate injected less energy. N28, which had a mismatching rate difference of $10.33 \mathrm{~W}$, produced 13.17 kWh $(10.67 \%)$ less than N20. N18, which had a mismatching rate difference of $5.79 \mathrm{~W}$, produced 23.07 
kWh $(5.91 \%)$ less than N27. N6, which had a mismatching rate difference of $4.26 \mathrm{~W}$, produced $9.18 \mathrm{kWh}(7.72 \%)$ less than $\mathrm{N} 1$. N10, which had a mismatching rate difference of $9.71 \mathrm{~W}$, produced $9.04 \mathrm{kWh}(7.50 \%)$ less than $\mathrm{N} 8$. However, there was no relationship between the values of MPF and the number of hot spots detected. As it is shown in N6, where has been obtained an MPF of $25.46 \mathrm{~W}$ and any hot spot was detected.

\section{Conclusion}

The main objective of the paper has been to perform a quality inspection of a PV plant composed of different PV modules classes. The procedure established has been based on three inspections; visual, IR thermography and electrical monitorization. Furthermore, a database has been analyzed to properly address the electrical mismatch issue.

Apart from the lack of cleaning and the front-side defects found in the visual inspection, it helped to develop a useful new PV module codification to address it easily.

IR thermographic inspection results have shown that less than $1 \%(0.76 \%)$ of the whole PV plant has been affected by thermal anomalies, of which $88 \%$ was categorized as hot spots.

The electrical monitoring results shown a homogeneous injection of electrical energy between inverters compared, but with a certain difference, since, inverters with higher values of MPF injected less energy.

\section{References}

[1] European Photovoltaic Industry Association (EPIA), "Global market outlook for photovoltaics until 2013," 2013.

[2] Solar Power Europe, "Global Market Outlook: 20192023," 2019.

[3] R. Moretón, E. Lorenzo, and J. Muñoz, "A study on the mismatch effect due to the use of different photovoltaic modules classes in large-scale solar parks," Wiley Online Libr., no. January 2012, pp. 2-6, 2012.

[4] M. Gostein, J. R. Caron, and B. Littmann, "Measuring soiling losses at utility-scale PV power plants," 2014 IEEE 40th Photovolt. Spec. Conf. PVSC 2014, pp. 885-890, 2014.

[5] G. Alvarez-Tey, J. A. Clavijo-Blanco, Á. Gil-García, C. García-Lopez, and R. Jimenez-Castañeda, "Electrical and Thermal Behaviour of Crystalline Photovoltaic Solar Modules in Shading Conditions," Appl. Sci., 2019.

[6] M. Davarifar, A. Rabhi, A. El-Hajjaji, and M. Dahmane, "Real-time model based fault diagnosis of PV panels using statistical signal processing," Proc. 2013 Int. Conf. Renew. Energy Res. Appl. ICRERA 2013, no. October, pp. 599604, 2013.

[7] IEA-PVPS Task 13, "Review of Failures of Photovoltaic Modules," Report IEA-PVPS T13-01, 2014.

[8] J. A. Tsanakas, L. Ha, and C. Buerhop, "Faults and infrared thermographic diagnosis in operating c-Si photovoltaic modules: A review of research and future challenges," Renew. Sustain. Energy Rev., vol. 62, pp. 695-709, 2016.

[9] E. S. Kopp, V. P. Lonij, A. E. Brooks, P. L. HidalgoGonzalez, and A. D. Cronin, "I-V curves and visual inspection of $250 \mathrm{PV}$ modules deployed over 2 years in tucson," Conf. Rec. IEEE Photovolt. Spec. Conf., pp.
3166-3171, 2012.

[10] Y. Hu et al., "Online Two-Section PV Array Fault Diagnosis with Optimized Voltage Sensor Locations," IEEE Trans. Ind. Electron., vol. 62, no. 11, pp. 72377246, 2015.

[11] R. Moretón, E. Lorenzo, and L. Narvarte, "Experimental observations on hot-spots and derived acceptance/rejection criteria," Sol. Energy, vol. 118, pp. 28-40, Aug. 2015.

[12] G. Acciani, G. B. Simione, and S. Vergura, "Thermographic Analysis of Photovoltaic Panels," Int. Conf. Renew. Energies Power Qual., vol. 1, no. 8, pp. 2009-2011, 2010.

[13] P. Sa, M. Piliougine, and J. Pela, "Analysis of degradation mechanisms of crystalline silicon PV modules after 12 years of operation in Southern Europe," no. January, pp. 658-666, 2011.

[14] C. Buerhop, D. Schlegel, M. Niess, C. Vodermayer, R. Weißmann, and C. J. Brabec, "Solar Energy Materials \& Solar Cells Reliability of IR-imaging of PV-plants under operating conditions," Sol. Energy Mater. Sol. Cells, vol. 107, pp. 154-164, 2012.

[15] P. Botsaris and J. Tsanakas, "Infrared thermography as an estimator technique of a photovoltaic module performance via operating temperature measurements," in 10th ECNDT Conference, 2010, p. 11.

[16] G. Alvarez-Tey, R. Jimenez-Castañeda, and J. Carpio, "Analysis of the configuration and the location of thermographic equipment for the inspection in photovoltaic systems," Infrared Phys. Technol., vol. 87, no. C, pp. 40-46, Oct. 2017.

[17] C. Buerhop, T. Pickel, M. Dalsass, H. Scheuerpflug, C. Camus, and C. J. Brabec, "AIR-PV-check: A quality inspection of PV-power plants without operation interruption," 2016 IEEE 43th Photovolt. Spec. Conf. PVSC 2016, 2016.

[18] M. Dalsass, H. Scheuerpflug, F. W. Fecher, C. BuerhopLutz, C. Camus, and C. J. Brabec, "Correlation between the generated string powers of a photovoltaic power plant and module defects detected by aerial thermography," in 2017 IEEE 44th Photovoltaic Specialist Conference, PVSC 2017, 2017, pp. 1-6.

[19] A. Sayyah, M. N. Horenstein, and M. K. Mazumder, "Energy yield loss caused by dust deposition on photovoltaic panels," Sol. Energy, vol. 107, pp. 576-604, 2014.

[20] CENELEC. European Committee for Electrotechnical Standardization, IEC 61215-1-1:2016. Terrestrial photovoltaic $(P V)$ modules. Design qualification and type approval. Part 1-1: Special requirements for testing of crystalline silicon photovoltaic (PV) modules. 2016.

[21] CENELEC. European Committee for Electrotechnical Standardization, IEC 61215-2:2017. Terrestrial photovoltaic $(P V)$ modules. Design qualification and type approval. Part 2: Test procedures. 2017.

[22] CENELEC. European Committee for Electrotechnical Standardization, IEC TS 62446-3. PV SystemsRequirements for testing, documentation and maintenance. Part 3: Photovoltaic modules and plants- Outdoor infrared thermography., vol. 7, no. 4. 2015.

[23] CENELEC. European Committee for Electrotechnical Standardization, IEC 61724-1:2017. Photovoltaic system performance - Part 1: Monitoring. 2018.

[24] S. Gallardo-Saavedra, L. Hernández-Callejo, and O. Duque-Perez, "Analysis and characterization of PV module defects by thermographic inspection," Rev. Fac. Ing. Univ. Antioquia, no. 93, pp. 92-104, 2019.

[25] S. Gallardo-saavedra and L. Hern, "Image Resolution Influence in Aerial Thermographic Inspections of Photovoltaic Plants," IEEE Trans. Ind. Informatics, vol. 14, no. 12, pp. 5678-5686, 2018. 